\title{
PROCESSO DE ANGÚSTIA/SOFRIMENTO MORAL EM ENFERMEIROS DA ESTRATÉGIA SAÚDE DA FAMÍLIA
}

Beatriz Santana Caçador¹, Flávia Regina de Souza Ramos², Maria José Menezes Brito ${ }^{3}$

Objetivo: estudo qualitativo, realizado na região metropolitana de Belo Horizonte, cujo objetivo foi analisar o processo de angústia/sofrimento moral em enfermeiros da saúde da família. Dados coletados com 13 enfermeiros por meio de entrevista com roteiro semiestruturado. Realizada análise por método filosófico-conceitual. Evidencia-se a relação entre sofrimento moral, prática profissional do enfermeiro na ESF e implicações identitárias evidenciando contradições na prática profissional do enfermeiro decorrente de constrangimentos organizacionais que provocam rupturas identitárias e comprometem o bem interno da profissão. Necessário identificar situações geradoras de sofrimento moral, criar dispositivos gerenciais de enfrentamento, evitando sua ocorrência e atenuando seus efeitos.

Descritores: Enfermagem; Sofrimento Moral; Estratégia Saúde da Família

THE PROCESS OF DISTRESS / MORAL SUFFERING IN NURSES OF FAMILY HEALTH STRATEGY: SUBJECTIVITY AND IDENTITY Objective: A qualitative study aimed to analyze the process of distress / mental suffering in the nurse health of the family. Conducted in the metropolitan region of Belo Horizonte. Data collected with 13 nurses through interviews with semi -structured script. Analysis by philosophical-conceptual method. Evident the moral suffering and professional nursing practice in the family health strategy has identity implications highlighting contradictions in professional nursing practice due to organizational constraints that cause identity breaks and undertake the internal profession well. Required to identify situations that moral suffering, create management coping devices, preventing their occurrence and mitigating their effects. Situations that cause mental suffering to create coping strategies and management of ethical problems devices, preventing their occurrence and mitigating their effects.

Descriptors: Nursing; Moral suffering; Family Health Strategy

\section{EL PROCESO DE ANGUSTIA SUFRIMIENTO MORAL EN LAS ENFERMERAS DE LA ESTRATEGIA SALUD DE LA FAMILIA: LA SUBJETIVIDAD Y LA IDENTIDAD}

Estudio cualitativo el objetivo de analizar el proceso de angustia sufrimiento / mental en las enfermeras de salud de la familia. Realizado en la región metropolitana de Belo Horizonte. Los datos recogidos con 13 enfermeras a través de entrevistas con guión semiestructurado. El análisis por el método concepto-filosofico. Es evidente el sufrimiento moral y práctica profesional de enfermería en el la enfermera de la salud de la familia: implicaciones de identidad destacando contradicciones en la práctica profesional de la enfermería debido a limitaciones de la organización que causan roturas de identidad y que ejerzan la profesión , así interno. Requerido para identificar situaciones que el sufrimiento moral, crear dispositivos de gestión de afrontamiento, la prevención de su ocurrencia y mitigar sus efectos.

Descriptores: Enfermería; Sufrimiento moral; Estrategia Salud de la Familia

${ }^{1}$ Enfermeira.Mestre em Enfermagem. Professora da Universidade Federal de Viçosa. E-mail: byacacador@gmail.com ${ }^{2}$ Enfermeira.Doutora em Filosofia e Enfermagem. Professora da Universidade Federal de Santa Catarina.

${ }^{3}$ Enfermeira.Doutora em Administração. Professora da Universidade Federal de Minas Gerais. 


\section{INTRODUÇÃO}

O sofrimento moral se manifesta como um desequilibrio psicológico vivenciado por indivíduos ao se depararem com obstáculos que impossibilitam ou dificultam sua intervenção na realidade e inviabilizam a adoção de atitudes e comportamentos considerados corretos e em consonância com seu julgamento moral $\left(^{(1,2)}\right.$

Evidenciam-se vivências de sofrimento moral em enfermeiros de Atenção Primária à Saúde (APS), os quais manifestam frustração e impotência, resultando em abandono do emprego ${ }^{(1,3)}$. Entretanto, a natureza e a extensão do processo de angústia e sofrimento moral entre enfermeiros da APS ainda não foram totalmente descritas e desveladas. Importa destacar que, com a mudança paradigmática que envolve a produção de cuidados em saúde, na atualidade, deslocou-se o centro da atenção à saúde do hospital para os ambulatórios e para a APS, fazendo com que o território onde as pessoas habitam e constroem seus modos de viver constitua o lugar primário de cuidados e, portanto, o lócus primário da ação moral ${ }^{(1,4)}$.

No Brasil, a Estratégia Saúde da Família (ESF) traduz o modelo de APS, tendo como eixo central a unidade familiar e como lócus operacional a esfera comunitária. Representa o ponto de atenção da rede com maior capilaridade na vida dos sujeitos, uma vez que se localiza no território onde os processos de viver, adoecer e cuidar são (re)construídos, reproduzidos e também transformados ${ }^{(5)}$

Tem-se como pressuposto que promover reflexões e construções teóricas sobre os aspectos relacionados ao mundo do trabalho que causam sofrimento e angústia tem como potencial sensibilizar para questões morais e éticas, promovendo o protagonismo e a transformação(2). A investigação tem como objetivo analisar o processo de angústia/sofrimento moral em enfermeiros no contexto da saúde da família, à luz da cartografia de sua produção e o processo de subjetivação e delineamento identitário a ela associados.

\section{METODOLOGIA}

Estudo qualitativo, desenvolvido em dez unidades de saúde da família de um município da região metropolitana de Belo Horizonte-MG. Participaram do estudo 13 enfermeiros da saúde da família. Os dados foram coletados por meio de entrevista aberta orientada por roteiro semiestruturado até que houvesse a saturação teórica dos mesmos ${ }^{(6)}$. Para análise dos dados, utilizou-se o método filosófico-conceitual ${ }^{(7)}$. Os preceitos éticos que regem as pesquisas com seres humanos foram respeitados de tal modo que o projeto de pesquisa foi submetido e aprovado pelo Comitê de Ética e Pesquisa com Seres Humanos e pelo Comitê de Ética da Prefeitura do município cenário deste estudo. A fim de garantir o anonimato dos participantes, os mesmos foram nomeados por $\mathrm{E}$ seguido do numero da entrevista realizada.

\section{RESULTADOS}

Pelos depoimentos é possivel perceber que na ESF os arranjos organizacionais têm impelido os enfermeiros a se distanciarem da essência de sua prática, tendo em vista a necessidade de suprir lacunas de um sistema de saúde em construção. A forma como a saúde da família tem sido estruturada confere ao enfermeiro um lugar de agenciador de fluxos. Assim, para se ter acesso ao profissional médico antes e primeiro, é necessário passar pelo enfermeiro, conforme relato de $\mathrm{El}$.

Porque a gente é um tudo, mas ao mesmo tempo não é nada, porque o pouo tem uma referência nossa, por exemplo, eles tem referência nossa como.., você só chega no médico se você passar no enfermeiro. Então a gente é só um entrave assim, uma porta pra eles, mas eles não enxergam a gente como essencial, cuidado, essas coisas, eles vê a gente tipo assim, pra você passar no médico você tem que passar com ele ali, entendeu? Então assim, não tem uma valorização, eu acho que a gente, a gente é tudo aqui ao mesmo tempo, ao mesmo tempo não é nada, dá essa angústia, sabe? Vê que a gente é que é o elo, mas eles não conseguem enxergar a gente como enfermeiro (El).

No que tange ao fazer profissional, percebe-se ainda que o enfermeiro incorpora práticas profissionais que fogem do exercício legal da profissão, constituindo, até mesmo, infrações éticas. No entanto, assume tal tipo de conduta mobilizado pelo vínculo com a responsabilização pela resolutividade da necessidade apresentada pelo usuário:

Às vezes a pessoa precisa, a gente pode manter receita por 30 dias. Todo enfermeiro tem autorização de manter a receita por trinta dias, mas eu não posso manter a receita por 30 dias se não tem o remédio aqui, porque na farmácia popular eles não aceitam o carimbo de mantido do enfermeiro, né? Eu tenho que pedir pro médico pra poder carimbar, ai eu transcrevo a receita, o médico carimba, né?(El).

Assumir para si elementos da prática profissional de outro trabalhador, mesmo que se justifique para satisfazer a necessidade imediata do usuário, pode, portanto, trazer implicações identitárias importantes. Pelo depoimento de El e E2 é possivel perceber que os enfermeiros infringem o código de ética profissional, assumindo atribuições do médico, a fim de suprir uma lacuna no processo de trabalho, tal qual pode ser evidenciado na fala a seguir:

Ah, vou ali prescrever esse remedinho aqui, prescrever esse remedinho aqui né? E você sabe que tem uma coisa que não está certa. Então assim, essa questão ética de prescrição 
de enfermagem eu acho que aqui é o que mais barra porque você acaba prescrevendo muito, para você dá conta, né? Da demanda da população e você tem aquele medo, você sabe que você tá prescrevendo a coisa certa é o que o médico faria mesmo, mas você sabe que não é sua função assim, que se der um problema vai dar um problema muito grande. Então isso acho que é o maior problema que eu tenho de ética assim eu acho que é o maior (E2).

É possivel perceber pelo relato de E2 que assumir a prática profissional designada a outra categoria é uma estratégia utilizada para dar uma resposta à demanda do usuário. Assim o enfermeiro afirma saber que está fazendo corretamente a atribuição do colega médico, embora reconheça estar infringindo seu código de ética. Essa situação the provoca sentimentos de angústia, pois reconhece que a prática assumida é para suprir a ausência do profissional médico.

Gera muito sofrimento. Muitas vezes, você fica angustiada sim, de eu sei que eu estou fazendo certo, mas eu não ... teoricamente eu não posso fazer isso, né? Claro que eu não, eu como enfermeira eu não posso e nem vou nunca prescrever um antibiótico, mas uma medicação que por exemplo, lá na farmácia eu compro sem receita, eu posso... esse remédio é bom, sabe? Então assim, essa questão de medicação que eu acho que não ... que atrapalha, que a gente não quer prescrever. Eu não quero ser o médico, prescrevendo, não é isso que eu quero, eu não prescrevo não é por isso, eu prescrevo por que eu não tenho quantidade suficiente de medico pra atender(E2).

Assumir atribuições do profissional médico em detrimento daquelas que competem ao enfermeiro na saúde da família provoca sentimentos de angústia e sofrimento, podendo trazer implicações identitárias importantes, pois provoca distorções de seu papel perante a equipe, a comunidade e a gestão. Ademais, fortalece a desvalorização de seu fazer específico, invisibilizado e escondido pelo próprio enfermeiro que se dedica ao fazer de outro profissional.

Falta um pouco deles (usuários) acreditarem mais no trabalho do enfermeiro, porque eles não é que desfazem, mas não dão muita credibilidade pro enfermeiro, acha que o enfermeiro não é nada, não sabe nada...não (E8).

Assim, o enfermeiro reconhece as contradições presentes em sua prática e o processo de desvalorização a ela associados, manifestando sofrimento, conforme relata E2:

Sofro muito, porque eu não vejo reconhecimento dentro da enfermagem, aqui assim, é triste eu falar isso (..) A gente fica nessa angústia, a gente fica nesse sofrimento diário de querer fazer as coisas, às vezes as pessoas não aceitam, não, não aceitam seu atendimento, eu quero passar para a médica, é direito dele, lógico que é, mas assim, vai passar pelo médico, o médico às vezes vai ter a mesma conduta que a minha, entendeu? É sofrido todos os dias, todos os dias, esse tanto de gente. A saúde está totalmente sucateada (E2).

Por outro lado, a fala de E9 sugere um movimento reacionário de fazer frente aos conflitos éticos que se apresentam em sua prática profissional. Analisando este depoimento à luz da construção teórica de Guattari(10)., podese inferir que a criação de terrenos singulares que, de algum modo, poderiam fazer frente às serializações subjetivas, dentro das quais a enfermagem encontra-se historicamente capturada.

Ah, muitas vezes assim eu já bati de frente, falando assim que eu não tenho formação para aquilo, eu não me formei para aquilo, eu não tenho conhecimento pra aquilo... às vezes acha que a gente tem que resolver tudo... não porque acha legal que a gente pode ajudar... mas pra eles trabalharem menos então assim, eu uso disso né... muitas vezes também não dá certo a pessoa não aceita... mas eu costumo falar isso. Olha eu não tenho conhecimento pra isso, eu só vou até aqui... essa parte aqui é sua né?(E9).

Desse modo, no presente estudo, o processo de angústia/ sofrimento moral em enfermeiros da saúde da família pertence à trama subjetiva de delineamento indentitário a partir dos enfrentamentos inscritos no cotidiano de trabalho, sobretudo, àqueles relacionados ao escopo e natureza da prática profissional do enfermeiro. Assim, em meio à angústia e sofrimento, o enfermeiro vai tecendo estratégias de resistência e enfrentamento, reconstruindo seu modo de ser profissional e reconfigurando as relações de poder inerentes ao processo de trabalho.

Mas já me angustiou muito...entendeu? Porque assim o médico queria que você agisse de uma forma, igual eu te falei, eu não me formei para isso. Eu não fiquei na faculdade para fazer transcrição de receita, para medir dados vitais, 
para ele só dar a receitinha. Isso faz parte do exame físico e ele aprendeu também a fazer. Então assim, já me angustiou muitas vezes. Na atualidade não, porque a gente tem uma boa relação. (E9).

\section{DISCUSSÃO}

A prática profissional na saúde da familia é tecida em meio ao desafio de superar os paradigmas do modelo de atenção à saúde médico centrado, o qual ainda se encontra presente no imaginário sócia, modulando a demanda por serviços de saúde. Essa realidade tem criado um espaço de práticas conflituosas para o enfermeiro, o qual se percebe impelido a suprir a essas demandas do sistema, distanciando seu fazer de suas atribuições legais. Esse contexto é fonte de angústia para o enfermeiro, que se percebe desvalorizado em seu papel profissional, o qual distancia-se de sua natureza e não é reconhecido socialmente. Vivenciar esse processo provoca sentimentos de angústia/sofrimento moral nos enfermeiros que julgam inapropriadas suas ações uma vez que experimentam sentimentos negativos por adotarem como prática uma postura considerada por eles moralmente inadequada(8):

Assumir a prática profissional do médico, seja por imposição organizacional, seja como forma de responder às necessidades do usuário, provoca rupturas identitárias no enfermeiro e fragiliza os laços de pertença com a profissão uma vez que fere o bem interno de sua prática profissional. Segundo Cortina, negligenciar o bem interno da profissão gera um distanciamento das virtudes inscritas na profissão. Há, pois, uma deturpação de valores quando a prática profissional de algum modo negligencia seu bem interno e assume como função a prática designada e legitimada a outra categoria(9)

Como prática social, a prática profissional prescinde do reconhecimento e legitimidade $\operatorname{social}^{(9)}$ e, na ausência desses imperativos de valorização, o profissional experimenta sentimentos de frustração e perda da autoestima. $O$ sofrimento moral ocorre quando não se consegue seguir a própria consciência mesmo sabendo a forma mais correta de $\operatorname{agir}^{(12,13)}$.

O sofrimento moral ameaça à integridade moral dos enfermeiros, distanciando-os de sua prática profissional e afetando a qualidade do cuidado(14). A prática profissional é uma atividade social baseada em princípios de cooperação entre sujeitos os quais assumem papéis diferenciados no conjunto da sociedade. Tais papéis prescindem, pois, de legitimação social. Toda prática profissional possui "bens internos" (identidade) e "bens externos" (prestígio e reconhecimento social) que caracterizam determinada profissão e participam do processo de reprodução da vida social de forma digna(9:123).

A necessidade do usuário é sinalizada como elemento motivador para que o enfermeiro incorpore práticas que não the competem, podendo gerar deturpações em sua imagem profissional e, por conseguinte, na forma como se percebe. A prática profissional é considerada por Cortina (2005)(9). Para Guattari, prática social e formações de subjetividade são processos indissociáveis(10). A subjetividade é tecida de forma abrangente, estabelecendo interfaces com o coletivo, ultrapassando a conotação habitual que a compreende sob aspectos psicologizantes, individualizado e natural ${ }^{(10)}$. Ademais, à luz da perspectiva teórica de Dubar (2005), pode-se inferir que esta realidade pode provocar rupturas na forma com a qual os enfermeiros tecem seus atos atribuição(11), influenciando a forma como se percebem e como constroem sua identidade no trabalho, conforme evidenciado na fala acima.

Em meio ao processo de angustia/sofrimento moral vivenciado por enfermeiros na saúde da família, o estudo revelou movimentos de resistência por meio de estratégias de enfrentamento, ora por embates diretos, ora de maneiras mais sutis, mas que buscam demarcar o terreno das práticas do enfermeiro. Nesse curso, o enfermeiro torna-se agente de produção da linha de montagem do desejo. Entretanto, esse processo não acontece isento de algum movimento de resistência. Ocorre que, por vezes, os inconscientes manifestam sua indignação denominada por Guatarri como afirmação ou invenção(10). Assim, há uma desmobilização em torno das linhas de montagem da subjetividade de tal modo que se configuram outras linhas e diferentes possibilidades de ser, perceber e estar no mundo. Evidencia-se, nesse processo, a reconfiguração de suas formas identitárias(11) a partir do movimento de resistência ao modelo hegemônico de prática 
que desvia a essência da profissão.

No bojo dessa trama, o cerne da linha de montagem da subjetividade é atacado a partir do momento em que afeta o "sistema de padronização do desejo"(10). O processo de deliberação moral marca, assim, um processo político delineado por forças de resistência as quais tem o potencial de ativar a construção de novos contornos de realidade na Enfermagem pós-moderna.

À luz do método filosófico-conceitual, articulou-se a abordagem filosófica de Gauattari com a definição de sofrimento moral para analisar a realidade estudada e sobre essa realidade pode-se inferir que o processo de angústia/ sofrimento moral está relacionado à tendência em manter determinadas linhas de montagem de subjetividade que algum modo padronizam o desejo, silenciando os inconscientes de seus protestos. O processo de deliberação moral acontece, por outro lado, quando há proeminência da força do desejo de tal modo em que, por meio da invenção, há uma desmontagem do processo de subjetivação dominante com criação de outros mundos. Assim, a padronização do desejo é atacada cada vez que o processo de criação acontece e subjetividades dissidentes são constituidas.

O cotidiano de trabalho do enfermeiro é marcado por diversas situações potencialmente geradoras de dilemas morais e conflitos éticos, as quais são potencialmente geradoras de sofrimento moral(15). Na saúde da família, as vivências de sofrimento moral estão relacionadas às contradições presentes no cotidiano do enfermeiro, o qual se percebe impelido a desviar-se de sua prática profissional e assumir ações de outros trabalhadores da equipe para suprir lacunas do sistema de saúde. Desse modo, o processo de subjetivação ocorre em meio a rupturas identitárias e movimentos de resistência, modulando formas de ser enfermeiro que ora reforçam a dominação instituída, ora transformando tal realidade.

\section{CONSIDERAÇÕES FINAIS}

O estudo analisou o processo de angústia/sofrimento moral de enfermeiros no contexto da ESF. No cotidiano de trabalho do enfermeiro na saúde da família, assumir prática profissional de outro membro da equipe pode gerar rupturas identitárias na medida em que o enfermeiro se desvia dos valores internos da profissão, fragilizando sua legitimidade e reconhecimento social. Desse modo os enfermeiros reforçam identidades há muito reconhecidas e até legitimadas, ainda que sob pena de contrapor os próprios ideais e consciência. Por outro lado, o processo de subjetivação pode indicar movimentos de reconstrução dos territórios singulares, imprimindo reconfigurações identitárias que mobilizam o enfrentamento. Necessário identificar situações geradoras de sofrimento moral, criar dispositivos gerenciais de enfrentamento no intuito de evitar sua ocorrência e atenuar seus efeitos.

\section{REFERÊNCIAS}

1. Laabs CA. Moral problems and distress among nurse practitioners in primary care. J Am Acad Nurse Pract. 2005; 17(2): 76-4.

2. Oh Y, Belgium L. Moral distress experienced by nurses: A quantitative literature review. Nursing Ethics. 2015;22(1):15-31

3. Laabs CA. Primary care nurse practitioners' integrity when faced with moral conflict. Nurs Ethics. 2007:14(6):795-9.

4. Nora CRD, Zoboli ELCP, Vieira M. Problemas éticos vivenciados por enfermeiros na atenção primária à saúde: revisão integrativa da literatura. Rev Gaúcha Enferm. 2015 mar;36(1):112-21.

5. Caçador BS, Brito MJM, Moreira DA, Rezende LC, Vilela GS. Ser enfermeiro na estratégia de saúde da familia: desafios e possibilidades. Rev Min Enferm. [Internet]. 2015 jul./set. [citado 2016 Mar 01]; 19(3), p. 612-619. Disponivel em: http://www.dx.doi.org/10. 5935/14 15-2762.20150047.

6. Fontanella BJB, Luchesi B M, Saidel MGB, Ricas J, Turato ER, Melo DG. Amostragem em pesquisas qualitativas: proposta de procedimentos para constatar saturação teórica. Cad Saúde Pública [Internet]. 2011 Feb [citado 2016 Mar 01] : 27(2): 388-4. Disponivel em: http://www.scielo.br/ scielo.php?script=sci_arttext\&pid=S0102-311X20110

00200020\&lng=en. http://dx.doi.org/10.1590/S0102-311X2011000200020.
7. Martins A. Filosofia e saúde: métodos genealógico e filosófico-conceitual. Cad. Saúde Pública. 2004:20(4):950-58.

8. Mccarthy J, Gastman CS. Moral distress: A review of the argumentbased nursing ethics literature. Nursing Ethics. 2015; 22(1):131-2.

9. Cortina A. Cidadãos do mundo: para uma teoria da cidadania. São Paulo: Edições Loyola; 2005.

10. Guattari F. Micropolítica: cartografias do desejo. Rio de Janeiro: Editora Vozes; 2005.

11. Dubar C. A crise das identidades: interpretação de uma mutação. São Paulo: Editora Universidade de São Paulo: 2005

12. Schaefer R, Vieira M. Competência ética como recurso de enfrentamento do Sofrimento moral em enfermagem. Texto Contexto Enferm.2015; 24(2): 563-73.

13. Wallis L. Moral distress in nursing. Am J Nurs. 2015;115(3):19-20.

14. Barlem ELD, Ramos FRS. Constructing a theoretical model of moral distress. Nursing Ethics. 2015;22(5):608-15.

15. Bresolin JZ, Dalmolin GL, Fruet IMA, Magnago TSBS, Rigue AC. Validade e confiabilidade do Moral Distress Scale adaptado em uma amostra de enfermeiros. Enferm Foco [Internet] 2016: 7 (1): 81-86. Disponivel em: http:// revista.portalcofen.gov.br/index.php/enfermagem/article/view/673/291 